\title{
MOVIMENTOS AMBIENTALISTAS NO RIO GRANDE DO SUL (DÉCADAS 1970-80)
}

\section{ENVIRONMENTALIST MOVEMENTS IN RIO GRANDE DO SUL (FROM 1970 THROUGH THE 1980's)}

DOI: http://dx.doi.org/10.15448/2178-3748.2018.1.24308

\author{
Elenita Malta Pereira \\ Doutora em História (UFRGS) - Professora na UFSC. \\ elenitamalta@gmail.com
}

\begin{abstract}
RESUMO: Este artigo examina a trajetória dos movimentos ambientalistas no Rio Grande do Sul, na segunda metade do século XX. Representa um esforço inicial para começar a preencher a lacuna sobre a história das principais entidades surgidas na capital e nas cidades interioranas, nas décadas de 1970 e 1980, na tentativa de traçar um panorama, mesmo que parcial, dos movimentos ambientalistas no Rio Grande do Sul, a partir da perspectiva da história ambiental. Para isso, são utilizadas pesquisas acadêmicas, fontes bibliográficas, documentos de arquivos e da internet.
\end{abstract}

PALAVRAS-CHAVE: Movimentos ambientalistas. Proteção à natureza. História ambiental

ABSTRACT: The present article examines the trajectory of environmentalist movements in Rio Grande do Sul in the second half of the $20^{\text {th }}$ century. This work represents an initial effort to start filling the gaps concerning the history of the first entities that appeared both in the capital and in inner cities, in the decades of 1970 and 1980, in an attempt to provide an overview, even if incomplete, of the environmentalist movements in Rio Grande do Sul from the perspective of environmental history. In order to do so, academic research, bibliographical sources, and documents from archives and from the Internet were used.

KEYWORDS: Environmentalist movements. Nature protection. Environmental history.

\section{INTRODUÇÃO}

Somente muito depois da Revolução Industrial, quando os sinais de deterioração do ambiente se tornaram visíveis para grande parte das pessoas e não apenas para observadores atentos, a necessidade de medidas para proteger a natureza tornou-se objeto de discussão. A consciência de uma crise de âmbito mundial foi o motivo pelo qual os debates sobre as questões ambientais começaram a se popularizar na década de 1960. O livro da bióloga norte-americana Rachel Carson, Primavera Silenciosa, publicado em 1962, pode ser considerado um dos principais marcos nesse sentido, colaborando para o surgimento de movimentos ambientalistas em todo o mundo, pois, ao denunciar os impactos ambientais do inseticida DDT nas lavouras, clamava por uma nova relação ética entre os seres humanos e a natureza. 
No Brasil e, principalmente, no caso do Rio Grande do Sul, foi muito importante o surgimento da Associação Gaúcha de Proteção ao Ambiente Natural (AGAPAN), em Porto Alegre, em 1971, que influenciou a criação de entidades na região metropolitana e interior do estado. No entanto, para além da fundação da AGAPAN, outros fatores devem ser citados para explicar o surgimento dos movimentos ambientalistas no interior do Rio Grande do Sul. Um deles foi a percepção cada vez mais evidente da crise ambiental e seus desdobramentos, tanto nos grandes centros urbanos como nos municípios interioranos. Outro fator foi a cobertura da imprensa à temática ambiental. Nos anos 1960-70, especialmente durante o contexto da ditadura militar, em que vigorou a censura aos meios de comunicação, a imprensa gaúcha voltou seu interesse para as questões ambientais, um tema que não era considerado "subversivo". Por fim, também relevante foi o papel das universidades, locus da discussão dos problemas ambientais por excelência. Principalmente os cursos voltados às ciências naturais, se pensarmos que boa parte dos fundadores da AGAPAN - e de outras entidades também eram professores de Biologia (Zoologia e Botânica) de universidades gaúchas (PEREIRA, 2016).

Como apontou Marcos Gerhardt (2011), só recentemente os historiadores começaram a se dedicar ao estudo do movimento ambientalista no Rio Grande do Sul. No entanto, a maioria das obras existentes concentra-se nas entidades surgidas em Porto Alegre. Ainda falta uma história mais aprofundada das associações existentes no interior do Estado e das relações destas com as primeiras. Este artigo representa um esforço inicial nesse sentido, ao apresentar uma breve trajetória de algumas das principais entidades surgidas na capital e nas cidades interioranas, na tentativa de traçar um panorama, mesmo que sucinto e longe de esgotar o assunto, do movimento ambientalista no Rio Grande do Sul, a partir da perspectiva da história ambiental, que trata em linhas gerais, "do papel e do lugar da natureza na vida humana" (WORSTER, 1991, p. 201).

Os movimentos ambientalistas estão entre os objetos de pesquisa que podem ser alvo do historiador ambiental. Eles começaram a surgir em meio ao boom de preocupações ambientais nos anos 1960-70, que Worster (2011) chamou de "Idade da ecologia". Associações em todo o mundo passaram a agir pela proteção à natureza em âmbito local e, ao mesmo tempo, questionar fatores políticos, econômicos e éticos que levariam a uma crise ecológica de alcance global. É importante destacar, nesse contexto, o reconhecimento de que uma das principais causas dessa crise seria a ética antropocêntrica que rege as relações entre humanidade e natureza. Por isso, muitos movimentos ambientalistas têm como objetivo defender a necessidade de uma nova ética, que parta do princípio de que tanto humanos como 
os demais elementos naturais tem direito à vida e à sobrevivência, uma ética biocêntrica (JUNGES, 2010).

O estudo dos movimentos ambientalistas contribui, dessa forma, para acessarmos ideias e práticas de indivíduos e grupos em prol da natureza, ao longo da história. No caso deste artigo, o recorte proposto é a emergência desses movimentos no Rio Grande do Sul, na segunda metade do século XX, mais especificamente durante as décadas de 1970-80. Nesse período foram criadas dezenas de associações, algumas ainda em funcionamento, outras de vida breve. Seria impossível abordar todas elas no espaço deste texto, portanto a escolha se deu a partir da menção nas fontes disponíveis à pesquisa. São utilizadas fontes bibliográficas e documentos de arquivos. ${ }^{1}$ Também será importante levar em conta pesquisas acadêmicas ${ }^{2}$ e faremos uso de fontes da internet, especialmente nos casos de entidades ambientalistas que ainda não foram alvo de estudos acadêmicos.

\section{MOVIMENTOS AMBIENTALISTAS NA CAPITAL, PORTO ALEGRE}

O ambientalismo é uma nova forma de movimento social descentralizado e multissetorial, que emergiu na década de 1970 no Brasil. Num contexto de ditadura militar, o movimento ambientalista foi um espaço que permitiu a manifestação pelo amparo à natureza. É importante esclarecer que não se trata de um movimento unificado, com atuação em bloco. Pelo contrário, uma das principais características desse movimento social é justamente o caráter diversificado dos sujeitos que militam, dos objetivos reivindicados e das estratégias de ação, como veremos ao longo deste texto.

No Brasil, desde o início do século XX, já havia associações voltadas à conservação do ambiente. Entidades como o Centro Excursionista do Rio de Janeiro, fundado em 1919; a Sociedade dos Amigos das Árvores, fundada em 1931 pelo botânico Alberto Sampaio; e a Sociedade Amigos de Alberto Torres, de 1932, foram importantes centros de incentivo à proteção do ambiente natural (SILVA, 2005, p. 191-92).

\footnotetext{
${ }^{1}$ Aqui são utilizados como fontes documentos localizados nos acervos: Arquivo Privado de José Lutzenberger (APJL); Museu Antropológico Diretor Pestana (MADP); Museu de Comunicação Social Hipólito José da Costa (MCSHJC).

${ }^{2}$ Alguns estudos já se debruçaram sobre os movimentos ambientalistas no Estado, tais como a dissertação de Guimarães (1993), sobre a Terraguar, de Novo Hamburgo; a tese de Prado (2008), sobre as crônicas jornalísticas de Henrique Roessler no Correio do Povo; a dissertação e tese de Pereira (2011b e 2016), respectivamente, estudos biográficos sobre Henrique Roessler e José Lutzenberger; a dissertação de Rückert (2007), que abordou diversos movimentos ambientalistas surgidos no Vale do rio dos Sinos, baseando-se, em boa parte, em depoimentos orais de ambientalistas da região; a dissertação de Estevam (2013), que analisou a crítica ambiental em Rio Grande por meio de crônicas jornalísticas escritas por ambientalistas da região, nos anos 1970-80.
}

Oficina do Historiador, Porto Alegre, EDIPUCRS, v. 11, n. 1, jan./jun. 2018, 
É importante ressaltar, no Rio Grande do Sul, as atuações de Henrique Roessler e Balduino Rambo, desenvolvidas nos anos 1930-60, pela "proteção à natureza". Roessler fundou a primeira entidade de defesa ambiental do Rio Grande do Sul, a União Protetora da Natureza (UPN), em 1955, em São Leopoldo, e foi protagonista de uma série de iniciativas conservacionistas no Estado, até seu falecimento, em 1963. Rambo, que era padre, professor e pesquisador da área de Botânica, alertou para a devastação das florestas gaúchas em suas obras e batalhou pela criação de parques naturais e instituições de pesquisa na área ambiental. As ações de Roessler e Rambo foram importantes e admiráveis, em suas épocas ${ }^{3}$, mas não podem ser analisadas como ambientalistas, pois ainda não faziam parte de um contexto em que as preocupações com o ambiente seriam temas debatidos por governos, empresas e sociedade, o que só aconteceria na virada dos anos 1960-70. Nesse período, começaram a ocorrer periodicamente uma série de conferências e eventos internacionais ${ }^{4}$, bem como a publicação de livros, manifestos e relatórios sobre o ambiente em todo o mundo ${ }^{5}$.

Em 1956, surgiu a Associação de Defesa da Flora e da Fauna (ADEFLORA), criada para dar força a uma campanha de defesa das florestas do Pontal do Paranapanema, no Estado de São Paulo. Um dos seus fundadores, Paulo Nogueira Neto, foi convidado a integrar o Conselho Florestal, ligado ao Governo de São Paulo. Formado em História Natural e em Direito, Nogueira Neto também foi o primeiro Secretário de Meio Ambiente no Brasil, atuando no cargo de 1973 a 1985.

Em 1958, foi criada a Fundação Brasileira para a Conservação da Natureza (FBCN), no Rio de Janeiro, que se tornou a entidade ambiental mais importante daquele contexto. A partir de 1966, a FBCN passou a publicar um boletim, através do qual a entidade se configurou em espaço de convergência da ideia de conservação da natureza no Brasil (FRANCO, DRUMMOND, 2009, p. 61). Essas entidades tiveram atuação importante, porém atuavam no âmbito do conservacionismo (uso racional dos elementos naturais) e preservacionismo (reserva de áreas naturais sem a presença humana); como a UPN de

\footnotetext{
${ }^{3}$ Para saber mais sobre a trajetória de Roessler e, em parte, de Rambo, consultar a biografia de Roessler (PEREIRA, 2013).

${ }^{4}$ Podemos citar, como exemplos, a Conferência Intergovernamental de Especialistas sobre as Bases Científicas para Uso e Conservação Racionais dos Recursos da Biosfera, realizada em 1968, em Paris, a Conferência das Nações Unidas sobre Meio Ambiente Humano, realizada em Estocolmo, Suécia, de 5 a 16 de junho de 1972, entre outras.

${ }^{5}$ O Clube de Roma publicou Limites do Crescimento, em 1972; Goldsmith et al publicaram A Blueprint for Survival, também em 1972; Uma Terra Somente, de Barbara Ward e René Dubós, foi publicado em 1973, entre muitas outras obras.
} 
Roessler, não podem ser consideradas ambientalistas - que se envolvem numa série de lutas de caráter político, enfocando as questões éticas, em prol da natureza ${ }^{6}$.

No Rio Grande do Sul, um dos marcos importantes para o movimento ambientalista foi a fundação da Associação Gaúcha de Proteção ao Ambiente Natural (AGAPAN), em 27 de abril de 1971. Liderada pelo engenheiro agrônomo José Lutzenberger e pelo advogado Augusto Carneiro, entre outros fundadores, a entidade se propunha a lutar pela defesa da "natureza ameaçada", nas formas de fauna, vegetação, solo, atmosfera, águas; pela constituição de parques e reservas naturais; pela salvação da humanidade da destruição; pela promoção da ecologia como "ciência da sobrevivência". Tinha como uma das principais finalidades "educar o povo para a preservação e conservação dos bens naturais" (FOLHA DA TARDE, 04/06/1971, MCSHJC).

A fundação da AGAPAN aconteceu num momento de popularização do conceito de "ecologia" no Brasil. O próprio uso da palavra "só se tornou corrente para o grande público no início dos anos 1970" (ACOT, 1990, p. 7). No Rio Grande do Sul, a ecologia ${ }^{7}$ foi uma novidade, que, transpondo os limiares acadêmicos (já fazia parte dos programas de estudo dos antigos cursos de História Natural do Estado), atraiu jovens engajados em movimentos sociais que emergiam naquele momento. ${ }^{8} \mathrm{O}$ discurso ambientalista aproximou também alguns antigos membros da UPN de Roessler, que se juntaram ao grupo fundador da nova entidade.

Para o ex-secretário da AGAPAN, Augusto Carneiro, a primeira reivindicação importante do movimento foi a luta contra o corte de árvores em Porto Alegre. Nos depoimentos orais que concedeu para nossas pesquisas, enfatizou sua preocupação: "a nossa

\footnotetext{
${ }^{6}$ Desde o final do século XIX, nos Estados Unidos, o debate estava dividido entre conservacionistas e preservacionistas, "os primeiros se preocupavam, sobretudo, com a racionalidade na utilização dos recursos naturais, enquanto os outros defendiam a natureza com os argumentos da fruição estética e da transcendência espiritual proporcionada pelos aspectos sublimes da natureza selvagem" (FRANCO, DRUMMOND, 2009, p. 46). Em geral, as entidades de defesa ambiental no Brasil atuavam no âmbito da conservação e da preservação de forma conjunta, diferente dos EUA - até os anos 1960. Com o boom da ecologia, nos anos 1970, as lutas passam a ganhar, paulatinamente, um viés mais ambientalista, ou seja, um leque mais amplo de lutas, considerando questões políticas e éticas em suas demandas.

${ }^{7}$ Segundo Rückert $(2015$, p. 7), "existem duas formas de pensarmos a Ecologia: podemos considerá-la como um segmento específico da Biologia focado no estudo dos ecossistemas e dos ciclos de energia da natureza; ou podemos pensá-la, de forma mais abrangente, como a Ciência da Biosfera. Em ambos os casos, existe uma concepção de natureza que contesta a fragmentação entre as partes do ambiente construída pelo racionalismo cartesiano e aponta para a valorização das interações entre o conjunto de seres vivos e os demais elementos naturais de um determinado ecossistema". No contexto em questão, "Ecologia" foi, também, sinônimo de defesa ambiental, citada inúmeras vezes por Lutzenberger, por exemplo, com esse sentido. Por isso, muitos passaram a chamar o conjunto de entidades que surgiram a partir dos anos 1970 de "movimento ecologista" ou "movimento ecológico".

${ }^{8}$ Nesse momento, marcado pela Guerra Fria, depois do "Maio de 68", ganhava força o movimento de contracultura que, assim como o movimento ecológico, era profundamente antindustrial, combatia o consumismo, a supremacia dos valores materiais, e questionava a racionalidade de uma sociedade que utilizava a ciência para produzir armas capazes de horríveis atrocidades nas guerras e insumos agrícolas que causavam danos ecológicos.
} 
reivindicação inicial eram as árvores. A primeira, e até hoje. Não há jeito de nós vencermos, isto é, acabarmos com as podas" (CARNEIRO, Entrevista à autora, 2005) ${ }^{9}$. Com efeito, dois meses após a fundação da entidade, seu primeiro presidente, José Lutzenberger, advertia no jornal Folha da Tarde (26/06/1971, MCSHJC) que a "poda está matando nossas árvores". A poda mal realizada fazia com que o tronco das árvores demorasse a cicatrizar, o que facilitava "a infiltração de bactérias e fungos" e, em pouco tempo, ocorria seu apodrecimento.

Em 04/02/1972, a Folha da Tarde publicava que "menos de um ano após ter sido fundada, a Associação Gaúcha ao Ambiente Natural - AGAPAN - considerava-se parcialmente vitoriosa na campanha contra a poda de árvores da cidade". Em 25 de fevereiro de 1975, o episódio em que o então estudante da UFRGS, o mineiro Carlos Dayrell, subiu em uma Tipuana, na avenida João Pessoa em Porto Alegre, impedindo que a mesma fosse cortada para dar lugar ao Viaduto Imperatriz Leopoldina, trouxe visibilidade nacional à causa e tornou-se um marco na luta ambiental brasileira (PEREIRA, 2009).

Dentre as inúmeras ações da AGAPAN, destaca-se, da fundação até meados dos anos 1980, o combate aos agrotóxicos, luta essa muito influenciada pela trajetória pessoal de seu primeiro presidente, José Lutzenberger, um engenheiro agrônomo que trabalhou na multinacional agroquímica BASF, de 1957 a 1970, emprego que o levou a morar na Alemanha, Venezuela e Marrocos. A partir de 1971, quando voltou ao Brasil e passou a representar a AGAPAN, tornou-se um dos seus principais opositores do uso desses produtos. Lutzenberger conheceu a indústria química "por dentro", o que garantia legitimidade a seu discurso contra os agrotóxicos. Com frequência, manifestava-se em palestra e eventos, alertando que os produtos matavam, além das "pragas", animais como perdizes, tico-ticos, sabiás, sapos e pererecas; mais do que isso, destruíam a vida do solo, as plantas nativas e envenenavam os cursos d'água.

Uma das lutas de maior visibilidade da AGAPAN, durante os anos 1970, foi a campanha contra a Celulose Borregaard (1973-74). A Borregaard, empresa de processamento de celulose norueguesa, instalou-se no município de Guaíba-RS, às margens do Lago de mesmo nome, e começou a operar em 16 de março de 1972. Foi um dos grandes projetos do período no Estado, incentivado pela ditadura militar, que não teve preocupação com o ambiente. Por conta do mau cheiro que exalava de sua chaminé e inundava o ambiente de Porto Alegre e região metropolitana, foi articulada uma grande campanha contra a Borregaard, que reuniu técnicos do governo, ativistas ambientais, entidades profissionais,

\footnotetext{
${ }^{9}$ Carneiro concedeu diversas entrevistas à autora, em diferentes oportunidades, para suas pesquisas, ao longo de 2005 a 2013.
} 
imprensa e políticos (foi aberta uma CPI na Assembleia Legislativa do RS). Com todo o clamor popular que sua poluição gerou, a empresa foi fechada em dezembro de 1973. Em 1974, foi reaberta e fechada mais uma vez, depois de comprometer-se a investir US\$3,5 milhões de dólares em equipamentos para voltar a operar. Após as investigações da CPI, os noruegueses abandonaram o negócio, ficando o controle acionário (51\%) nas mãos do Montepio da Família Militar (MFM), o que possibilitou a nacionalização da empresa, pois $44 \%$ já correspondiam ao dinheiro injetado pelo BNDES no projeto (BONNES, HASSE, 2002, p. 30). Depois disso, a empresa melhorou seus controles antipoluição e passou por diferentes proprietários e nomes (PEREIRA, 2014).

Outra importante entidade ambientalista porto-alegrense foi a Associação Democrática Feminina Gaúcha (ADFG), fundada em 1964, mas que, nos anos 1970, assumiu a preocupação ecológica como uma de suas "bandeiras"10. Inicialmente, as integrantes faziam assistência social em creches, clubes de mães, escolas, etc. Em 1972, após assistirem a palestra "Os quatro princípios básicos da ecologia", proferida por Lutzenberger, elas começaram a interessar-se pela ecologia e, em 1974, mesmo ano em que Magda Renner assumiu como presidente da ADFG, criaram um departamento para tratar do tema dentro da associação.

A ADFG e a AGAPAN trabalharam em conjunto em algumas campanhas, uma delas, que ganhou destaque naquele contexto foi a "Operação Hermenegildo", organizada com o objetivo de chamar a atenção da sociedade gaúcha para a mortandade de peixes e animais na Praia do Hermenegildo, em abril de 1978, no litoral de Santa Vitória do Palmar-RS. Em clima de mistério, o governo declarou que o motivo para as mortes era a "Maré Vermelha", um fenômeno natural. Os ambientalistas não aceitaram a explicação, pois estavam convictos de que a causa do desastre teria sido o naufrágio do navio Taquari, contendo carga química altamente perigosa da multinacional Dow Chemical. A campanha promovida pelos ambientalistas não conseguiu provar sua hipótese, tampouco a versão do governo do Estado foi plenamente aceita. Apesar de não ter sido uma operação malsucedida, os ambientalistas não conseguiram que prevalecesse a sua versão do real motivo pelo qual teria ocorrido o desastre ecológico (PEREIRA, 2009).

Ao lado da militância, começam a surgir importantes publicações sobre a temática ambiental. O lançamento de Fim do Futuro? Manifesto Ecológico Brasileiro em 1976, escrito por Lutzenberger, foi acontecimento de grande impacto para o movimento ambientalista

\footnotetext{
${ }^{10}$ Em 1983, a ADFG passou a ser o único membro brasileiro da Federação Internacional Friends of the Earth e, em 1998, atualizou seus estatutos e passou a chamar-se Núcleo Amigos da Terra, ou NAT/Brasil.
}

Oficina do Historiador, Porto Alegre, EDIPUCRS, v. 11, n. 1, jan./jun. 2018, 
brasileiro. Lançado em formato tabloide (10.000 exemplares) e livro (3.000 cópias), em Cotia-SP e Porto Alegre-RS, era um "documento de luta", que utilizava uma linguagem deliberada para chocar e esclarecer sobre a gravidade dos problemas ambientais. Num plano mais profundo, Fim do Futuro? lançou as bases teóricas para a difusão da ecologia como movimento político no Brasil.

O livro se divide em duas partes: na primeira, "A demolição da Ecosfera", são apontados os principais problemas causadores da crise ambiental; já a segunda parte do livro, chamada "Reconquista do Futuro", é dedicada à exposição das soluções para vencer essa crise. Na obra, Lutzenberger critica e condena o consumismo, o aumento populacional, a energia atômica, o apagamento das tradições culturais dos povos indígenas e o modelo de desenvolvimento adotado no país, como se fosse "uma religião fanática, com fervor missionário e força de convicção como nunca houve na História da Humanidade" (LUTZENBERGER, 1976, p. 16).

Em Fim do futuro?, Lutzenberger lançou seu conceito de ecologia, que entendia a partir da ligação dos humanos com a natureza, em bases holísticas: ambos, em sua visão, não deveriam estar separados, pois faziam parte da Terra, da "Vida", formando uma unidade, um “todo indivisível”. A partir do entendimento desse conceito básico, seus leitores chegariam à conscientização ecológica. Em especial, interessava a Lutzenberger introduzir essa concepção entre os jovens, futuros ambientalistas em potencial; nesse sentido, o livro pode ser pensado como uma obra de formação, para instrumentalizar, dar argumentos mais qualificados à luta, baseados na ciência Ecologia. Com a primeira edição esgotada em menos de um ano, o livro teve ampla circulação naquele contexto (PEREIRA, 2012).

Ainda nos anos 1970, surgiram várias entidades voltadas à proteção ambiental em Porto Alegre, como a Associação Nacional de Apoio ao Índio (ANAÍ, em maio de 1977), a Cooperativa Coolmeia (1978) e o Movimento Kaa-Eté (1979). A ANAÍ surgiu a partir das discussões do "Seminário O Índio Brasileiro: Um Sobrevivente?", organizado pela Assembleia Legislativa do Rio Grande do Sul. Entre outros fundadores, destacou-se a ambientalista Hilda Zimmermann, que também participara da criação da AGAPAN. No contexto de ditadura militar dos anos 1970, o governo federal executava uma política de “integração do índio à sociedade nacional”, o que resultou na perda dos direitos originários sobre suas terras (ZIMMERMANN, 2012, p. 64). Sob a presidência de Hilda, a ANAÍ lutou pelo resgate das terras indígenas, sua não integração à sociedade capitalista e a manutenção de seus direitos. 
A Cooperativa Coolmeia, fundada em 1978 por influência das campanhas da AGAPAN contra os agrotóxicos, dedicava-se principalmente à divulgação e comercialização da alimentação saudável, orgânica, sem agrotóxicos. Conforme Claudia Dreier (2010, p. 17), a Coolmeia utilizava um modelo inédito, no qual reunia três categorias de associados: produtores, consumidores e operacionais, que trabalhavam para manter as atividades da cooperativa. A Coolmeia foi a organizadora e fundadora da Feira dos Agricultores Ecologistas (FAE), em 16 de outubro de 1989, Dia Mundial da Alimentação. A Feira mantém-se em atividade, durante todos os sábados, pela manhã, no canteiro central da primeira quadra da avenida José Bonifácio, no Parque da Redenção (DREIER, 2010, p. 17).

Já o Movimento Kaa-Eté surgiu nas dependências do Colégio Júlio de Castilhos, em abril de 1979, por iniciativa dos estudantes, motivados pelas professoras de Biologia e Geografia. Segundo Braun, Kindel e Guimarães (1998, p. 223), a emergência do grupo se deveu a três fatores: ao excelente trabalho desenvolvido pela professora de Geografia da escola à época, a uma palestra de Lutzenberger sobre a Amazônia assistida pelos alunos em dezembro de 1978 e a uma greve dos professores do Estado, em março de 1979. O nome da entidade foi mencionado por Lutzenberger na referida palestra: Kaa-Eté, palavra que significa mata-virgem em tupi guarani. As principais atividades do grupo eram palestras realizadas na própria escola sobre temáticas diversas, a produção de um jornal regular e a participação em passeatas e atividades de outros movimentos (BRAUN, KINDEL, GUIMARÃES, 1998, p. 223-24).

Percebe-se nesses movimentos a influência da AGAPAN e de Lutzenberger. Utilizando espaços disponíveis na mídia, a entidade conseguiu projetar-se não apenas localmente como modelo para a formação de novos grupos, mas também nas regiões metropolitanas e interior do Estado. A AGAPAN foi a entidade ambientalista mais importante do período1970-80 no Rio Grande do Sul. A participação de seus membros em inúmeros debates e lutas - especialmente José Lutzenberger, figura de maior projeção naquele contexto - levou à disseminação do movimento, como veremos a seguir.

\section{MOVIMENTOS AMBIENTALISTAS NA REGIÃO METROPOLITANA DO ESTADO}

Em julho de 1971, três meses depois da AGAPAN ter surgido em Porto Alegre, foi fundado em São Leopoldo, no Vale do Rio dos Sinos, um "Núcleo Leopoldense", a AGAPAN-NL. O biólogo Renato Petry Leal foi o primeiro presidente da entidade, e alguns 
de seus membros haviam sido sócios da UPN de Roessler, entre 1955-63. Em suas lutas iniciais, o grupo mobilizou-se em torno dos problemas ambientais de São Leopoldo, entre eles o agravamento da poluição do rio dos Sinos; o avanço sobre áreas pantanosas: o aterramento do Banhado São Miguel e a construção de aterros sanitários em áreas de banhado; a luta pela arborização de São Leopoldo e a preservação de áreas verdes, como o Matinho Padre Reus ${ }^{11}$ (RÜCKERT, 2007, p. 21).

Como mencionamos anteriormente, São Leopoldo já havia abrigado a UPN de Roessler. Para homenageá-la, e para que não houvesse confusão com a associação da capital, em 1986, os integrantes resolveram alterar o nome da entidade para União Protetora do Ambiente Natural (UPAN). Márcio Link, um dos sócios-fundadores da nova entidade, afirmou que "a troca do nome atendia a uma necessidade que os militantes de ambas as entidades sentiram em função da confusão causada pelo nome em comum" (LINK, 2008, p. 105). Houve uma renovação quando Carlos Cardoso Aveline assumiu a presidência da entidade. Além da troca de nome, houve mudanças, "reformulação do estatuto, busca por apoio financeiro internacional e remuneração de alguns militantes” (RÜCKERT, 2007, p. 16).

Outra entidade surgida no Vale do Rio dos Sinos foi o Movimento Roessler, em 1978 em Novo Hamburgo, a partir da repercussão causada pela Operação Hermenegildo. Os primeiros sócios foram um grupo de alunos da escola Fundação Evangélica, motivados por seu professor de ecologia, Kurt Schmeling, que fora membro da UPN (PEREIRA, 2013, p. 182). Eles fizeram circular um abaixo assinado exigindo que o governo estadual esclarecesse o motivo da mortandade de animais na praia de Hermenegildo (RÜCKERT, 2007, p. 15). O nome da entidade também é uma referência explícita a Roessler e a intenção do grupo de Novo Hamburgo era prestar uma homenagear a seu trabalho de proteção à natureza (PEREIRA, 2011a, p. 139).

Uma importante ação conjunta da UPAN e do Movimento Roessler foi a campanha para a criação do "Parcão", em Novo Hamburgo. A partir do trabalho acadêmico da estudante de Arquitetura Jussara Kley, em 1985, surgiu a ideia da transformação de uma área verde do município (na época, pertencente a uma empresa, a Paquetá Empreendimentos Imobiliários) em parque, para fins de preservação ambiental e lazer. O projeto tomou forma e foi apresentado aos vereadores da cidade. Ao mesmo tempo, entidades ambientalistas da região (UPAN e Movimento Roessler) e pessoas simpáticas à ideia formaram o chamado "grupo do parque", e passaram a reivindicar sua aprovação. Por meio de "caminhadas ecológicas" e da

\footnotetext{
${ }^{11}$ Nome popular da área de mata que fica próxima ao templo Padre Reus, em São Leopoldo, que recebeu o nome oficial de Parque Municipal Henrique Luiz Roessler (RÜCKERT, 2007, p. 21).
} 
Fundação Pró-Parque, o grupo pressionou o poder público municipal a desapropriar o espaço, assumindo "o compromisso de fazer da área um espaço de lazer e de preservação ambiental" (RÜCKERT, 2007, p. 40). O parque foi criado oficialmente em abril de 1990 e recebeu o nome de "Parque Henrique Luiz Roessler".

Na luta acima mencionada, bem como na constituição de grupos ambientalistas em São Leopoldo e Novo Hamburgo, podemos perceber a referência ao trabalho de Roessler. Houve aí um interessante processo de "enquadramento de memória", envolvendo tanto a denominação das entidades, como na constituição de lugares de memória para homenageá-lo (PEREIRA, 2013).

No final da década de 1980, também no Vale do Rio dos Sinos, em Novo Hamburgo, surgiu a Terraguar Associação Ecológica. O grupo, formado por moradores do Bairro Canudos, aliados à comunidade luterana do mesmo bairro, iniciou uma campanha de combate à poluição do arroio Pampa, um dos principais afluentes do rio dos Sinos (RÜCKERT, 2007, p. 15-16). Em 1989, a Terraguar também se engajou na luta contra a poluição causada pelo aterro sanitário na vila Kröeff, localizado num banhado a 800 metros do rio dos Sinos. Chamado de "lixão", o aterro recebia 180 toneladas diárias de lixo hospitalar. Nessa luta, a Terraguar uniu-se à UPAN e Associação dos Moradores da Vila Kröeff, sendo que as duas primeiras moveram uma ação civil pública contra a contaminação do banhado e do rio (GUIMARÃES, 1993, p. 37-38).

O problema do "lixão" envolveu também discussões entre a prefeitura local e o Movimento Roessler, que procurou esclarecer a população do município sobre os riscos do aterro sanitário. Um dos fundadores da AGAPAN, o engenheiro agrônomo e ambientalista José Lutzenberger foi chamado para que fosse encontrada uma alternativa de descarte que evitasse a poluição do rio dos $\operatorname{Sinos}^{12}$. Lutzenberger aceitou o convite para assessorar a prefeitura municipal no tratamento do lixo depositado no aterro (na proposta, ele permaneceria no mesmo local) e também na instalação de um projeto de tratamento do arroio Pampa. No entanto, tais projetos receberam críticas da UPAN, Terraguar e Associação de Moradores da Vila Kröeff, que não concordavam com a permanência do aterro na Vila ${ }^{13}$. Após muitas discussões, a prefeitura construiu um aterro sanitário e uma central de reciclagem em uma antiga pedreira de outro bairro de Novo Hamburgo, o bairro Roselândia.

\footnotetext{
${ }^{12}$ Lutzenberger possuía uma empresa de reciclagem de resíduos industriais, que eram transformados em adubos para a agricultura, a "Vida Produtos Biológicos Ltda.", por meio da qual iria assessorar a Prefeitura na solução do problema causado pelo "lixão".

${ }^{13}$ Para acompanhar os detalhes sobre as discordâncias entre as entidades ambientalistas, quanto ao problema do aterro sanitário na Vila Kröeff, consultar Guimarães (1993).
} 
Segundo Rückert (2007, p. 31), "esse aterro excedeu seu limite, e o problema do destino do lixo em Novo Hamburgo continua aguardando uma solução mais adequada".

Outra entidade surgida na região metropolitana foi a Associação de Preservação da Natureza do Vale do Gravataí - APNVG, fundada em 14 de junho de 1979, com sede em Gravataí-RS. Dentre as primeiras ações da APNVG, destaca-se a participação em uma "Procissão Ecológica" em 1980, em conjunto com o movimento eclesial de base de Cachoeirinha. Esse evento teve como objetivo sensibilizar as autoridades e a população para os riscos de sobrevivência que o rio Gravataí estava sujeito, em razão da drenagem do Banhado Grande realizada no ano de 1962, da construção de um canal çãque alterava seu leito original, e da poluição gerada pelo descarte do esgoto da cidade no rio sem tratamento (ANPVG, Online, 2012). Em 1983, a APNVG promoveu o I Ciclo Estadual de Estudos e Debates sobre os banhados do Rio Grande do Sul, em Gravataí (WEBER, 2004, p. 63). Grande parte da atuação da entidade foi voltada para a preservação do rio Gravataí (luta contra o desmatamento das matas ciliares, drenagem de banhados, despejo de esgotos in natura, etc.). Mas também operava em outras demandas, que afetavam as demais cidades da região metropolitana de Porto Alegre, como o combate à supressão de matas nativas para instalação de loteamentos de terrenos, especialmente em Gravataí, Cachoeirinha, Alvorada e Viamão, em 1985, e para a instalação do Distrito Industrial de Canoas, em 1988 (WEBER, 2004, p. 65).

Essas lutas levaram alguns jovens, preocupados com a perda de espaços naturais, a fundar uma nova entidade, o Movimento Ecológico Livre (MEL-UHIRY), em Cachoeirinha, por volta de 1985-86. UHIRY é um vocábulo do dialeto ianomâmi, que significa "terra". Em 1989, o MEL organizou um abaixo-assinado contra as agressões a dois parques nativos locais (Tancredo Neves e Parque da Matriz). Após angariar 800 assinaturas, o documento "motivou uma denúncia ao IBAMA, que enviou técnicos à cidade, cujo relatório, de 14 de junho do mesmo ano, confirmou as denúncias" (WEBER, 2004, p. 68).

\section{MOVIMENTOS AMBIENTALISTAS NO INTERIOR DO RS}

Em seguida à fundação de movimentos em Porto Alegre e região metropolitana, houve a disseminação de entidades pelo interior do Rio Grande do Sul, nas décadas de 1970-80: em várias cidades foram criadas "PANs". Elas não eram filiais da AGAPAN Porto Alegre, mas certamente sua atuação inspirou e influenciou pessoas sensibilizadas à questão ambiental a criarem associações. Algumas ainda possuem atuação hoje, como, por exemplo, a Associação 
Ijuiense de Proteção ao Ambiente Natural - AIPAN, de Ijuí (fundada em 1973), e a Associação Bento Gonçalvense de Proteção ao Ambiente Natural - ABEPAN, de Bento Gonçalves (criada em 1989). Outras encerraram suas atividades, caso da AGAPAN Rio Grande (fundada em 1978).

Segundo Lutzenberger, em correspondência enviada a Ludwig Reichardt Filho, em 05/07/1973 (MADP) ${ }^{14}$, na época estavam em formação grupos ambientalistas em Santa Maria, Caxias do Sul, Alegrete e Passo Fundo. A AIPAN foi fundada em dezembro de 1973, em Ijuí, e realizou sua primeira assembleia no início do ano seguinte (GERHARDT, 2011, p. 2). Reichardt Filho foi o primeiro presidente da AIPAN, que configurou-se como "um movimento social urbano, de classe média, sintonizado com os problemas de seu tempo, de atuação limitada ao foco que seu estatuto estabelecia: proteger o ambiente natural da devastadora ação humana, por meio da educação e da informação, a chamada “conscientização"” (GERHARDT, 2011, p. 10-11). Dentre as muitas atividades em que se envolveu, durante sua trajetória de mais de 40 anos, destacam-se a produção de mudas para arborização urbana e reflorestamento e a participação em debates sobre temas como reciclagem e destino do lixo, produção agroecológica e poluição ambiental (AIPAN, Online, S/Data).

Apesar da política de descentralização da AGAPAN, orientada por influência de Lutzenberger, em 1975, foram criados núcleos da entidade em Pelotas e Erechim. Pelo que a correspondência entre o secretário da AGAPAN, Sergio Beck, e os representantes das novas entidades indica, elas levavam apenas o nome da entidade da capital, acrescido do de sua cidade, por exemplo, "AGAPAN - Pelotas". Havia mesmo um modelo de carta que era remetido para os novos ambientalistas, com palavras de incentivo: "a adesão por parte de vocês à luta ambiental representa para nós motivo de grande estímulo e profunda satisfação"; oferecimento de ajuda: "colocamo-nos à disposição, no sentido de colaborar em tudo que for possível, para que essa feliz iniciativa seja levada adiante e obtenha pleno êxito"; sugestões de atuação junto à imprensa, na denúncia dos problemas ambientais; envio de material de leitura, como exemplares da revista Sobrevivência ${ }^{15}$ e uma relação de livros sobre ecologia, além de cópia dos Estatutos da AGAPAN, para servir de modelo às novas associações (BECK, Sergio. Carta a Antonio Costa, núcleo Pelotas. Porto Alegre, 30/09/1975, APJL; BECK, Sergio. Carta ao núcleo de Erechim. Porto Alegre, 01/10/1975, APJL). No entanto, além dessa acolhida

\footnotetext{
${ }^{14}$ Ludwig Reichardt Filho procurou a orientação da AGAPAN Porto Alegre para fundar a AIPAN.

${ }^{15}$ Revista editada pela AGAPAN ente as décadas de 1970 e 1980.
} 
inicial, não havia um envolvimento direto da AGAPAN na atuação das associações criadas nas cidades interioranas.

Nos anos 1980, sugiram, no Sul do Estado, o Centro de Estudos Ambientais - CEA (1983) e o Núcleo de Educação e Monitoramento Ambiental - NEMA (1985), ambos na cidade de Rio Grande e ainda em atividade. O CEA protagonizou diversas campanhas locais pela proteção da praia do Cassino e das lagoas gaúchas, como o "Movimento pela proteção das dunas de Rio Grande e do Balneário do Cassino", Movimentos "Lagoa limpa”, "Abrace a lagoa", e "Eu também quero a lagoa despoluída", etc. Em cooperação com a Fundação Universidade de Rio Grande (FURG), o CEA organizou o I Curso em Extensão em Direito Ambiental no Estado, em 1990. O grupo tem forte atuação em atividades de educação ambiental, no debate de políticas ecológicas e projetos em parceria com a UNESCO e o Ministério do Meio Ambiente (PEREIRA, 2011a).

O NEMA surgiu da iniciativa de um grupo de estudantes do curso de Oceanologia da FURG, preocupados com a situação ambiental do município. Rio Grande vinha passando por um surto desenvolvimentista desde os anos 1970, com as obras de infraestrutura implantadas pela ditadura militar (ampliação do Superporto de Rio Grande, instalação de um distrito industrial, entre outras). Esse modelo de progresso imposto pelos generais/presidentes à época foi alvo de ampla crítica por ambientalistas militantes na cidade (ESTEVAM, 2013). O NEMA atua em toda a costa brasileira, principalmente na região costeira do Rio Grande do Sul, através de projetos apoiados em ações coordenadas de educação, monitoramento, pesquisa e conservação, com vistas à gestão ambiental (NEMA, Online, S/Data).

No Norte do Estado, em 21 de setembro de 1983, ocorreu a fundação do Grupo Ecológico Sentinela dos Pampas - GESP, em Passo Fundo. A entidade surgiu da aproximação de um grupo de jovens, nos anos 1980, que, em seus debates, posicionavam-se contra questões como energia nuclear, armamentismo e a utilização inadequada dos elementos naturais. O nome é inspirado no pássaro símbolo do Rio Grande do Sul, o quero-quero (chamado também de "sentinela dos pampas"), conhecido por cuidar e defender ruidosamente seu ninho. O grupo, que se auto atribui a missão de "ecologizar a cidade", inspirando-se no quero-quero, "tem tentado fazer alarido, chamando a atenção da comunidade em geral para as questões ambientais" (GESP, Online).

Nos anos 1980, também surgiram novas "PANs". Em São Borja, fronteira com a Argentina, foi fundada a Associação São-Borjense de Proteção ao Ambiente Natural (ASPAN), em 21 de setembro de 1987, ocasião em que o engenheiro agrônomo Darci Bergmann foi eleito seu primeiro presidente. É interessante constatar semelhanças na 
trajetória de Bergmann e Lutzenberger. Assim como o fundador da AGAPAN, ele também havia trabalhado numa multinacional de agrotóxicos e, com o tempo, passou a questionar o uso desses produtos. Por influência do exemplo de Lutzenberger, Bergmann redirecionou sua atuação para a ecologia, atuando em palestras e campanhas na área ambiental. A ASPAN surgiu do sucesso da campanha "Plante uma vida, plante uma árvore", que mobilizou a sociedade local no plantio de cerca de 18 mil espécimes arbóreas nativas. A entidade atua até hoje, nas áreas de educação ambiental e no plantio de árvores nativas na região (ASPAN, Online).

Também a União Pedritense de Proteção ao Ambiente Natural (UPPAN) foi criada em 22 de julho de 1989, na cidade de Dom Pedrito, no Sudoeste do estado. Entre suas primeiras campanhas, a entidade priorizou a proteção do rio que passa pelo município, luta que levou a criação do Comitê de Gerenciamento da Bacia Hidrográfica do rio Santa Maria. A UPPAN se envolveu em projetos de reciclagem e coleta seletiva de resíduos sólidos e líquidos, incentivo às práticas orgânicas na agricultura e atividades de educação ambiental, como a organização de seminários, palestras, passeios ciclísticos, caminhadas com recolhimento de lixo, distribuição de panfletos, etc. (UPPAN. 20 anos da UPPAN, 2011).

Na região Nordeste, da Serra Gaúcha, surgiu a Associação Bento Gonçalvense de Proteção ao Ambiente Natural (ABEPAN), criada em 13 de setembro de 1989 e ainda em atuação. Sua principal liderança foi o político Luiz Augusto Signor, que a presidiu da fundação até seu falecimento, em 2015. Entre seus principais objetivos, constam a defesa da qualidade do ar, do solo e da água, a preservação da flora nativa, fauna e ecossistemas da região. As atividades da ABEPAN abarcam Bento Gonçalves e municípios da região Nordeste do Estado (Flores da Cunha, Cotiporã, Garibaldi, Carlos Barbosa e Nova Roma do Sul, entre outras cidades vizinhas), na forma de palestras a escolas, empresas e associações, saídas de campo e outras ações envolvendo educação ambiental (MORO, BORTOLINI, 2010).

Na primeira metade da década de 1980, quando já havia um bom número de associações, teve início a realização de encontros estaduais. Desses encontros, surgiu uma organização congregadora das entidades, a Assembleia Permanente de Entidades em Defesa do Meio Ambiente - APEDeMA/RS, em 1990.

O I Encontro Estadual de Entidades Ecologistas (EEEE) foi realizado nos dias 8 e 9 de maio de 1984, em Santa Maria. O evento foi promovido por uma entidade local chamada "Irmão Sol, Irmão Lua" e AGAPAN. Segundo Pizarro (2010), 110 ambientalistas participaram do encontro, representando associações de diversas cidades do Estado. No evento, foram discutidas e aprovadas cerca de trinta moções. Dentre elas, destacaram-se a 
solicitação à UNESCO que tornasse o Banhado do Taim "patrimônio comum da Humanidade"; moção de repúdio ao uso de agrotóxicos na hidrelétrica de Tucuruí, na Amazônia; proibição da caça às baleias; correspondência aos ministros e senadores dando apoio à aprovação da Lei 7747/82 (Lei Estadual dos agrotóxicos); etc. No X EEEE, realizado em Caxias do Sul em 1989, foram estabelecidos critérios para as entidades ambientalistas, o que possibilitou a criação da APEDeMA/RS, no final de 1990, em Novo Hamburgo.

\section{A ÊNFASE NA EDUCAÇÃO AMBIENTAL}

Podemos perceber que a AGAPAN exerceu grande influência nas entidades criadas no interior do estado. Seja nas orientações sobre como fundar uma nova associação, seja no nome, às vezes o mesmo, outras vezes quase igual, na denominação "PAN", seja na ênfase nos problemas ambientais locais, a AGAPAN foi fonte de inspiração para os novos ambientalistas. Podemos perceber também, em várias dessas entidades, a ênfase no caráter educativo de suas ações, expresso na dedicação a atividades na área de educação ambiental.

Muitas entidades têm promovido debates para conscientizar a população sobre a poluição das águas - no caso do CEA, por exemplo, preocupado com a lagoa dos Patos e oceano Atlântico -; a necessidade de plantio de árvores, nas zonas urbana e rural das cidades em que atuam, como incentivam a AIPAN e a ASPAN; a importância da separação do lixo e sua reciclagem, enfatizado pela UPPAN, entre outras temáticas locais importantes, trabalhadas em palestras em escolas, empresas e associações. Esse enfoque na conscientização ambiental já estava presente nas entidades criadas nos anos 1970, especialmente na AGAPAN. Nesses primeiros movimentos, percebia-se um "caráter educativo-ambiental" nas ações desenvolvidas, um processo com o objetivo de "alcançar um estágio de conscientização plena, pois, somente assim, ocorreria a mudança dos valores, das atitudes e da moral de todas as pessoas" (GUIMARÃES, NOAL, 2000, p. 9). Como vimos, a ética antropocêntrica era percebida, pelos ambientalistas, como a causa mais profunda da crise ambiental. Por isso, eles acreditavam que a ênfase no caráter educativo poderia levar à reversão do quadro, com a adoção de uma nova ética, biocêntrica.

No entanto, como conceito, é somente nos anos 1980 que começa a configurar-se um espaço próprio da "educação ambiental” (CARVALHO, 2002, p. 298). Diversos atores, entre eles, as entidades ambientalistas passam a organizar eventos e disseminar práticas educativas visando a proteção ambiental. É o momento de abertura política no Brasil, que recém deixava para trás um regime ditatorial de duas décadas. Depois das grandes lutas dos anos 
1970, encabeçadas pela AGAPAN (contra os agrotóxicos, a Celulose Borregaard, a devastação da Amazônia, etc.), o Estado começou a apropriar-se das questões ambientais, criando fóruns para sua discussão, como os Conselhos municipais, estadual e federal de meio ambiente e toda uma legislação começa a ser construída para a proteção da natureza, que passa a ser tutelada na Carta Magna de 1988.

A partir dos anos 1980, além dos movimentos ambientalistas e do Estado, outros agentes passaram a ter interesse na questão ambiental, atuando em redes, o que autores como Eduardo Viola e Hector Leis (1995) entenderam como a passagem de uma abordagem bissetorial para a multissetorialização do ambientalismo, aspecto percebido por eles como um avanço. Entretanto, Agripa Alexandre (2003) defende que esse processo levou, em sentido contrário, à banalização da problemática socioambiental e à perda de radicalidade do movimento ambientalista, na medida em que o ambiente passou a ser fator importante para impulsionar o lucro de empresas, a publicidade, demandas da mídia, etc.

Portanto, nesse novo cenário, o papel dos movimentos ambientalistas, para além de trazer os problemas ambientais à tona e promover sua crítica, por meio da imprensa - modo mais comum de atuação nos anos 1970, principalmente da AGAPAN -, na década seguinte, passou também a enfatizar a divulgação de práticas de educação ambiental nas cidades em que atuavam, atuando em redes com diferentes setores sociais (poder público, empresas, publicidade, mídia, etc.). Essa estratégia de privilegiar demandas locais e práticas educativas parece ter sido a tônica dos movimentos ambientalistas tanto na capital como nas cidades do interior do Estado (mas especialmente nestas), que, diante da enorme complexidade dos problemas ambientais em âmbito global, faziam o possível, ou seja, incentivavam atitudes que promovessem uma interação mais consciente entre humanos e natureza, por meio da educação ambiental.

\section{CONSIDERAÇÕES FINAIS}

Diante do exposto, podemos perceber que no Rio Grande do Sul há uma trajetória importante de proteção à natureza. Aqui, analisamos brevemente os projetos de alguns indivíduos e organizações da sociedade civil que influenciaram dinâmicas ambientalistas na segunda metade do século XX.

A existência de um grupo de ex-integrantes da UPN de Roessler, de profissionais preocupados com a questão ambiental (biólogos, jornalistas, advogados, professores universitários, etc.), aliado à volta de José Lutzenberger ao Brasil em 1971 foram fatores 
importantes para o surgimento da AGAPAN, que desencadeou várias atuações em prol da natureza na capital do Rio Grande do Sul, capazes de repercutir na constituição de uma série de entidades semelhantes no interior do Estado. Esses movimentos ambientalistas não compunham um movimento coeso e unificado - muito pelo contrário: a diversidade de indivíduos, reivindicações e estratégias era a sua marca - e, com isso, foram capazes de condensar formas de manifestações políticas democráticas e inclusivas. Ao unir-se aos mais diferentes grupos pelas mais diversas causas, em espaços variados, esses movimentos ambientalistas representaram, no contexto repressivo da ditadura militar brasileira importantes lugares de exercício da cidadania.

Tanto as entidades da região metropolitana como do interior enfatizaram a proposição e atividades educativo-ambientais de alcance local, visando a conscientização de crianças, jovens e adultos. Com isso, esperavam contribuir para reverter a devastação e contribuir para a internalização de comportamentos mais responsáveis para com o "ambiente natural", tais como a separação e a reciclagem do lixo, o plantio de árvores, o cuidado com as águas, entre outros.

Após a redemocratização, os movimentos ambientalistas ainda seguiram ocupando um lugar de cidadania relevante na sociedade. Ocorreu a profissionalização dos militantes e a atuação em torno de projetos, muitas vezes, articulados com outras ONGs, além da parceria com universidades, empresas, fundações e governos, o que significou, para alguns autores, um avanço; para outros, retrocesso e perda da radicalidade.

Como indicado desde o início, este texto pretendeu traçar um panorama dos movimentos ambientalistas no Rio Grande do Sul. À medida que os historiadores realizarem pesquisas mais pontuais sobre cada uma das entidades, especialmente as do interior do estado, a partir de arquivos públicos, privados e de entrevistas a seus fundadores e membros, essa história deverá tornar-se mais completa e complexa, expondo as continuidades, conflitos e contradições que a permeiam. Se este artigo puder ser um incentivo inicial a essas pesquisas, sua escrita já terá valido a pena.

\section{REFERÊNCIAS BIBLIOGRÁFICAS}

ACOT, Pascal. História da Ecologia. Rio de Janeiro: Editora Campus, 1990.

ALEXANDRE, Agripa. A perda da radicalidade do movimento ambientalista brasileiro. Uma nova contribuição à crítica do movimento. Ambiente \& Educação (FURG), Rio Grande RS, v. 8, p. 73-94, n. 2003. 
BONES, Elmar, HASSE, Geraldo. Pioneiros da Ecologia: Breve História do Movimento Ambientalista no Rio Grande do Sul. Porto Alegre: Já Editores, 2002.

BRAUN, Maria C., KINDEL, Eunice, GUIMARÃES, Leandro B. Sobre o "Roessler" e o "Kaa-Eté": Dois movimentos ambientais escolares. Episteme. Porto Alegre, v. 3, n. 7, p. 220$230,1998$.

CARVALHO, Isabel Cristina de Mora. A invenção do sujeito ecológico: sentidos e trajetórias em educação ambiental. Tese (Doutorado em Educação). PPG Educação da UFRGS, Porto Alegre, 2000.

DREIER, Cláudia. A paisagem construída na produção alternativa praticada por integrantes da Feira dos Agricultores Ecologistas em Porto Alegre-RS. Trabalho de Conclusão de Curso em Geografia. Porto Alegre, UFRGS, 2010.

ESTEVAM, Bread Soares. História, crítica e a Educação Ambiental sob o prisma das crônicas ecológicas da associação gaúcha de proteção ao ambiente natural no extremo sul do Brasil (1978-81). Dissertação (Mestrado em Educação Ambiental). Rio Grande, FURG, 2013.

FRANCO, José Luiz, DRUMMOND, José Augusto. O cuidado da natureza: A Fundação Brasileira para a Conservação da Natureza e a experiência conservacionista no Brasil (19581992). Textos de História, UNB, Vol. 17, n. 1, 2009, p. 59-84.

GERHARDT, Marcos. Um olhar sobre a história dos movimentos ecologistas no Rio Grande do Sul. Anais do XXVI Simpósio Nacional de História da ANPUH. São Paulo, USP, 2011.

GUIMARÃES, Leandro Belinaso; NOAL, Fernando Oliveira. Um olhar sobre os ideais educativos constituídos pelos movimentos ecologistas nos anos setenta. In: Reunião Anual da ANPEd, 23., 2000, Caxambu. Anais eletrônicos... Caxambu, 2000.

GUIIMARÃES, Vera Maria. O movimento ambientalista em um momento de transição: análise de um conflito. Dissertação de Mestrado. Programa de Pós-Graduação em Sociologia Política. Universidade Federal de Santa Catarina, Florianópolis, 1993.

JUNGES, José Roque. (Bio) Ética Ambiental. São Leopoldo: Editora da Unisinos, 2010.

LINK, Márcio. Para além do ambientalismo: uma história em duas décadas. São Leopoldo: Oikos, 2008.

LUTZENBERGER, José. Fim do Futuro? Manifesto Ecológico Brasileiro. Porto Alegre: Editora Movimento, 1976.

PEREIRA, Elenita Malta. A árvore da João Pessoa e a Operação Hermenegildo: dois episódios de resistência do movimento ambientalista gaúcho. In: VII Mostra de Pesquisa do 
APERS: Produzindo História a partir de fontes primárias. Porto Alegre: Editora CORAG, 2009.

Da proteção à natureza ao desenvolvimento sustentável: A defesa ambiental no Rio Grande do Sul. Tempos Históricos. Unioeste, Volume 15, 2011a, p. 117-153.

. Um protetor da natureza: Trajetória e Memória de Henrique Luiz Roessler.

Dissertação de Mestrado. Porto Alegre, Programa de Pós-Graduação em História da UFRGS, $2011 b$.

. O Manifesto Ecológico Brasileiro de José Lutzenberger como um instrumento de luta do movimento ecológico: Ideias e circulação inicial (1976-77). Anais do $2^{o}$ Simpósio Internacional de História Ambiental e Migrações (CD-ROOM). Florianópolis, UFSC, 2012, p. $1636-1657$.

Roessler: O homem que amava a natureza. São Leopoldo: Oikos, 2013.

Medio Ambiente y Dictadura en Brasil: La lucha contra la Celulosa Borregaard (1972-75). HIb: Revista de Historia Iberoamericana, Santiago-Chile, v. 7, p. 147-166, 2014.

. A ética da convivência ecossustentável: uma biografia de José Lutzenberger. Tese de Doutorado em História. Programa de Pós-Graduação em História, Universidade Federal do Rio Grande do Sul. Porto Alegre, 2016.

PRADO, Daniel Porciúncula. A figueira e o machado - raízes da educação ambiental no Sul do Brasil: Práticas educativas e militância ambiental na perspectiva do cronista Henrique Luiz Roessler. Programa de Pós-Graduação em Educação Ambiental. Universidade Federal do Rio Grande, 2008.

RÜCKERT, Fabiano. História e memória do ambientalismo no Vale do Rio dos Sinos. Dissertação de Mestrado. PPG em História da UNISINOS, São Leopoldo, 2007.

O ambientalismo em três escalas de análise. Cadernos $I H U$, São Leopoldo, no 51 , 2015.

SILVA, Zélia Lopes da. As percepções das elites brasileiras dos anos de 1930 sobre a natureza: das projeções simbólicas às normas para o seu uso. In: ARRUDA, Gilmar (Org.). Natureza, fronteiras e territórios: imagens e narrativas. Londrina: Editora da UEL, 2005.

VIOLA Eduardo; LEIS, Héctor. O ambientalismo multissetorial no Brasil para além da Rio92: o desafio de uma estratégia globalista viável. In: VIOLA, E.; LEIS, H.; SCHERERWARREN, I; GUIVANT, J.; VIEIRA, P. F.; KRISCHKE, P. J. (orgs.). Meio ambiente, desenvolvimento e cidadania: desafio para as Ciências Sociais. São Paulo: Cortez, 1995.

WEBER, Regina. Os rapazes da RS-030: jovens metropolitanos nos anos 80. Porto Alegre: Editora da UFRGS, 2004. 
WORSTER, Donald. Para fazer história ambiental. In: Estudos Históricos, Rio de Janeiro, vol. 4, n. 8, 1991, p. 200.

WORSTER, Donald. Nature's economy: A history of ecological ideas. Second Edition. Cambridge-UK: Cambridge University Press, $2011 \mathrm{~b}$.

ZIMMERMANN, Lívia. Ações que mudaram a história: A saga de Hilda E. Wrasse Zimmermann. Porto Alegre: Karioka, 2012.

\section{FONTES DA INTERNET}

AIPAN. Associados efetivos da AIPAN em 2016. Disponível em: $<$ http://www.aipan.org.br/associados $>$. Acesso em 19 março 2016.

APNVG. Você conhece Apn-vg?. Publicado em 23 out. 2012. Disponível em: <http://apnvg.blogspot.com.br/2012_10_01_archive.html>. Acesso em 19 março 2016.

ASPAN. Histórico - A consciência ambiental em São Borja. S/Data. Disponível em: $<$ http://aspanrs.blogspot.com.br/p/consciencia-ambiental-em-sao-borja.html $>$. Acesso em 25/04/2015.

GESP. Disponível em: 〈http://www.sentineladospampas.eco.br/p/historico.html>. Acesso em $30 / 04 / 2014$.

MORO, Cristiane; BORTOLINI, Kátia. Luis Augusto Signor: de faxineiro a ambientalista. Integração da Serra. Publicado em 02/12/2010. Disponível em: <http://integracaodaserra.blogspot.com.br/2010/12/luis-augusto-signor-de-faxineiro.html > Acesso em 20/04/2015.

NEMA. Filosofia. Disponível em: 〈http://www.nema-rs.org.br/sobre>. Acesso em 19 março 2016.

PIZARRO, James. Primeiro Encontro Estadual de Ecologia no Rio Grande do Sul. Publicado em 29 julho 2010. Disponível em: <http://professorpizarro.blogspot.com.br/2010/07/primeiroencontro-estadual-de-ecologia.html>. Acesso em 20 março 2016.

UPPAN. 20 anos da UPPAN. Publicado em 15 de julho de 2011. Disponível em: <http://uppandompedrito.blogspot.com.br/>. Acesso em 25/04/2015.

\section{FONTES DOCUMENTAIS}

BECK, Sergio. Carta a Antonio Costa. Porto Alegre, 30/09/1975 (APJL).

BECK, Sergio. Carta ao núcleo de Erechim. Porto Alegre, 01/10/1975 (APJL). 
FOLHA DA TARDE. Porto Alegre tem associação para proteger a natureza. Porto Alegre, 04/06/1971 (MCSHJC).

FOLHA DA TARDE. Agrônomo adverte: poda está matando nossas árvores. Porto Alegre, 26/06/1971 (MCSHJC).

FOLHA DA TARDE. AGAPAN acha que sua campanha contra a poda foi vitoriosa. Porto Alegre, 04/02/1972 (MCSHJC).

LUTZENBERGER, José. Carta a Ludwig Reichardt Filho. Porto Alegre, 05/07/1973 (MADP).

FONTE ORAL

CARNEIRO, Augusto. Entrevista à autora. Porto Alegre, 2005.

ARTIGO ENVIADO EM: 16/06/2016

ARTIGO ACEITO PARA PUBLICAÇÃO EM: 05/02/2017 